\title{
A Study on Key Factors Affecting Enterprise's Adoption of Electronic Commerce on Regional Level
}

\author{
Ming Li \\ JiLin Business And Technology College, ChangChun ,China \\ 120857715@qq.com
}

Keywords: Affect, Electronic Commerce, Adoption, Regional Factors.

\begin{abstract}
The key point of enterprise's adoption of electronic commerce is the value innovation. In order to improve the success ratio of enterprise's adoption of electronic commerce, the enterprise needs to start from both the internal and external, distribute resource effectively, improve the environmental adaptation and follow the rule of independent innovation. In this thesis, the factors affecting enterprise's adoption of electronic commerce on the regional level are put forward. The research in this thesis can effectively answer the question of "what are the key factors affecting enterprise's adoption of electronic commerce on the regional level" in theory and can contribute to the decision-making of the enterprise managers and relevant departments on the electronic commerce in practice.
\end{abstract}

\section{Introduction}

Along with the development of technology, IT technology is widely applied in the production and operation of the enterprise, and the electronic commerce originated from Europe and America is gradually promoted on a global scale and is adopted, promoted and innovated by enterprises in many countries, including China. Hence, the business model changes radically and a new kind of business model that is the electronic commerce pattern is formed. The importance of electronic commerce adoption is self-evident, however, not every enterprise can keep up with the trend of the times and cope with the new changes of the competitive environment skillfully; whether and how to adopt the electronic commerce has become a major task for the enterprises. Thereinto, the strategic analysis before the electronic commerce adoption is crucial adjective and the enterprise needs to understand the key influencing factors of electronic commerce adoption so as to adopt the electronic commerce pattern that is suitable for the self-development and can improve the competitiveness. However, so far, there are few studies on the key factors affecting and restricting the enterprise's adoption of electronic commerce, especially the academic achievements under the Chinese background, therefore, it is studied in this thesis to fill in the gap of theoretical research in this field.

\section{Factors Affecting Electronic Commerce Adoption on Regional Level}

At present, some scholars have studied the adoption of electronic commerce in some regions or countries in the world and have identified some key success factors affecting the electronic commerce adoption in the regional, geographic or social level. Since the national conditions are different, the electronic commerce adoption and its key influencing factors are also different. Although the electronic commerce can bring the competitive advantages to the enterprises and provide more value for the consumers, many enterprises in the developing countries make little use of the electronic commerce. The main reason is that the electronic commerce is not only a technological innovation, but also a business model innovation; its adoption, promotion and popularization in a country is a big change that has its own diffusion path and may meet the economic, political, cultural and cognitive hurdles[1]. The factors affecting the enterprise's adoption of electronic commerce on the regional level mainly include:

Demographic Factor. During the adoption process of the electronic commerce, the demographic factor plays a vital role. The foundation of the electronic commerce is not to build a web site, but to promote the sale of products. Only when people are willing to purchase the products 
or services of the enterprise, the economic resource is changed into wealth and the articles are turned into goods. The consumption habit and preference are different in different regions, therefore, the enterprise should study the consumer behaviors carefully and grasp the consumption habits and preference of the local consumers accurately before adopting the electronic commerce in order to have a definite object in view and select the appropriate electronic commerce pattern. Many factors can affect people's decision on online shopping, such as price of product or service, convenience of online shopping, risk of shopping, consumption habit and preference, self-efficacy, computer use level and service level and quality. Although the network is popular, many people surf the Internet to browse and gather information, send and receive e-mails and play online games, however, few people do business through the internet. The internet is not fully functioned because people are lack of trust for the electronic commerce. Take China for example, the online shopping is a new thing and many consumers are used to the face to face contact with the merchant, therefore, both the trust problem of online shopping and the security of online transaction may hinder the popularization of electronic commerce. [2]

According to the online shopping experience, the consumers are divided into two types, the potential consumers and the general consumers; the technology acceptance model (TAM) is used to determine the factors that affect the consumer's decision on online shopping, including the convenience and usefulness, online shopping experience and self-efficacy. Both the tangible goods and relevant services can be purchased through the website; thereinto, the risk of shopping is the main problem considered by the consumers when purchasing the tangible goods through the website and the convenience is the main problem when purchasing the services. In table 1, the relevant factors affecting shopping are summarized.

Table 1 Factors Affecting Online Shopping

\begin{tabular}{|c|c|}
\hline Influencing factors & Contents \\
\hline Attitude on innovation & $\begin{array}{l}\text { Consumer's attitude on electronic commerce; } \\
\text { acceptance for information technology innovation; } \\
\text { value criterion. }\end{array}$ \\
\hline Risk of shopping & $\begin{array}{l}\text { Economic factor, social factor, product feature, } \\
\text { character, credit card security }\end{array}$ \\
\hline Product information & Product price, quality and category \\
\hline Previous shopping experience & $\begin{array}{l}\text { Required time for shopping, comfortleve, product } \\
\text { validity, effect, compatibility, entertainment, } \\
\text { satisfaction degree. }\end{array}$ \\
\hline Service quality of merchant & $\begin{array}{l}\text { Reaction speed for customer demand, reliability, } \\
\text { insurance. }\end{array}$ \\
\hline
\end{tabular}

Sociocultural Factor. When adopting the electronic commerce, the enterprise must take the local social culture into consideration because the culture can have a significant impact on the consumer's decision on shopping through affecting the risk consciousness of the consumer, subjective norm and self-efficacy. There are more studies on the influence of culture diversity on electronic commerce adoption. Take B2B market in Taiwan as example, it is thought that the traditional Chinese culture, government function and industry characteristic all play important roles in electronic commerce adoption and the factors related with the cultural background hinder the popularization of electronic commerce in China, including difficult to come into contact with computer network, lack of trust and information sharing, unable to tolerate failure and impossible to meet the challenge of quick environmental change. Take Chinese online customers for example, the five factor theory of Hofstede for evaluating different cultural frameworks is applied to study the influence of national culture on consumer's acceptance for electronic commerce, including convenience, usefulness, trust and usage intention.

Government Factor. The government plays an important role in the adoption and popularization of electronic commerce innovation, however, since the cognition of different governments on new scientific and technological revolution is different, their reactions are also 
different and thus the electronic commerce adoption is different in different countries due to the "opportunism" of the government in the presence of new scientific and technological revolution. Take China for example, it implements the socialistic market economy system which is different from the other countries and thus the government plays a more important role in the electronic commerce adoption; the participation degree of government in commercial activities and the usage of the administrative and coercive means may affect the electronic commerce adoption. On the whole, the innovation abilities of the middle and small-sized enterprises in China are poor, because there are not suitable places for the innovation activities of middle and small-sized enterprises in the national innovation system and the resource allocations of the innovation activities are dissociated from the national innovation system, thought by Tang Xiaoyun. Hence, China needs to construct the independent system of innovation policy of middle and small-sized enterprises within the framework of national innovation system that satisfies the construction of innovation country and meet the requirement of the evolution and adjustment of policy goal, including IT technology.

Infrastructure Factor. The construction of material bases that are suitable for the healthy operation of electronic commerce includes Internet infrastructure construction, correlative technique and logistics distribution system, however, the infrastructure construction of electronic commerce in most developing countries is backward due to the influence and restriction of the low social, economic and cultural level. Take the B2B electronic commerce market in China for example, it is thought that the lack of relevant infrastructure construction, technique and service is the key factor affecting Chinese electronic commerce adoption. At present, the electronic commerce adoption in China has obvious regional differences and the service enterprises of electronic commerce are mainly distributed in Yangtze River Delta, Pearl River Delta, Beijing, Shanghai and other developed provinces and cities; the backwardness of the infrastructure construction definitely hinders the popularization of electronic commerce in economically undeveloped areas and restricts the electronic commerce adoption of the local enterprise. In general, besides the above-mentioned influencing factors, there are many regional factors affecting the electronic commerce adoption, such as economy, legislation, policy and technology. The adoption and popularization of electronic commerce in any country or region is not smooth, instead it is as winding as the "S"curve and has a lot of obstacles to overcome[3]. After summarizing the studies of relevant scholars, the factors affecting the electronic commerce adoption are summarized in this thesis, shown in table 2.

Table 2 Relevant Regional Factors Affecting Electronic Commerce Adoption

\begin{tabular}{|c|c|}
\hline $\begin{array}{l}\text { Affecting } \\
\text { Factors }\end{array}$ & Features \\
\hline $\begin{array}{l}\text { Economic } \\
\text { structure }\end{array}$ & $\begin{array}{l}\text { The electronic commerce has different requirements for different sectors, } \\
\text { therefore, the diffusion rate is different. For example, in the manufacturing } \\
\text { industry, the technical requirement is high, the international communication is } \\
\text { frequent and thus it is easy to promote the electronic commerce. However, in the } \\
\text { countries focusing on traditional industries, such as agriculture, the electronic } \\
\text { commerce is promoted slowly. }\end{array}$ \\
\hline $\begin{array}{l}\text { Infrastructure } \\
\text { construction }\end{array}$ & $\begin{array}{l}\text { The electronic commerce has high requirements on the network facilities, rear } \\
\text { services, transportation, logistics and payment. }\end{array}$ \\
\hline $\begin{array}{c}\text { Population } \\
\text { structure }\end{array}$ & $\begin{array}{l}\text { The dense population, high income and good education are all beneficial to the } \\
\text { promotion of electronic commerce. }\end{array}$ \\
\hline Culture & nal culture can affect consumer behavior and choice. \\
\hline System & $\begin{array}{l}\text { For the promotion and popularization of electronic commerce, it is required to } \\
\text { establish and perfect the complete legal and financial systems which can } \\
\text { promote the trade contacts and the formation of good international reputation. }\end{array}$ \\
\hline Market size & $\begin{array}{l}\text { If the market is narrow, it is difficult to innovate and promote the electronic } \\
\text { commerce. }\end{array}$ \\
\hline $\begin{array}{l}\text { Government } \\
\text { policy }\end{array}$ & $\begin{array}{l}\text { The government supports, including the development strategy programming of } \\
\text { electronic commerce, advocacy for electronic commerce, providing relevant } \\
\text { services, allowance and financial incentive and tax preference, can promote the }\end{array}$ \\
\hline
\end{tabular}




\section{Conclusions and Suggestions}

In this thesis, it is recognized from a new angle and the key influencing factor of enterprise's adoption of electronic commerce is put forward, that is region factor. The specific circumstance is shown in figure 1.

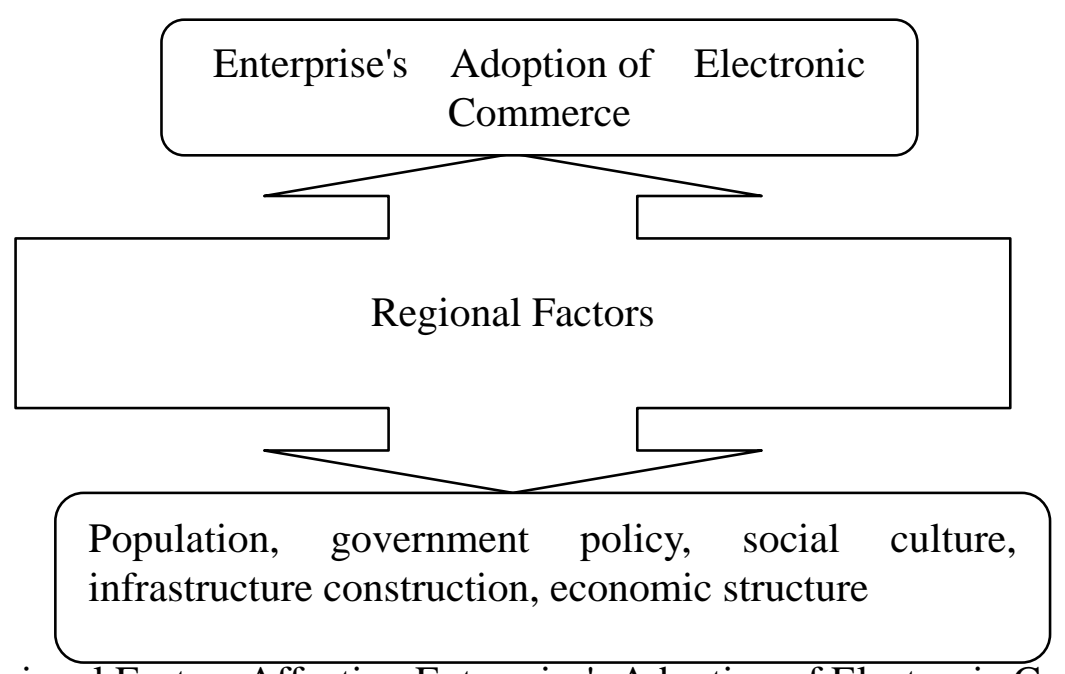

Fig. 1 Regional Factors Affecting Enterprise's Adoption of Electronic Commerce

Based on the above analysis, the following conclusions can be obtained: the key point of enterprise's adoption of electronic commerce is value innovation, that is to realize the self-value of the enterprise based on the realization and improvement of consumer value. If the enterprise adopts the electronic commerce innovation, it means that it will improve the value that the consumer can perceive and the enterprise must formulate and implement the new development strategy before adopting the electronic commerce. The accurate strategy analysis is the foundation for the success of electronic commerce adoption, therefore, the enterprise should take the relevant restraining factors of electronic commerce adoption into consideration and formulate the effective electronic commerce strategies.

\section{References}

[1] X.Y. Tang. An Analysis on Innovation Policies of Small and Medium-sized Enterprises in China - Based on Samples from 1997 to 2008. Studies in Science of Science, 2011( 12) : 1807-1812.

[2] G. Zhang, C. Chen. A Study on Influence of Entrepreneur Ability on Enterprise Advantage in Competition. China Soft Science, 2011( 10):164-171.

[3] S. Guo. Who Says Elephant Can’t Dance. Beijing: China CITIC Press, 2010. 